\title{
ARTIGO
}

dOI https://doi.org/10.22481/praxis.v15i32.5056

\section{A EDUCAÇÃO INTEGRAL NA URSS: EXPERIÊNCIAS DE MAKARENKO NA COLÔNIA GORKI E NA COMUNA DZERJINSKI}

\author{
INTEGRAL EDUCATION IN THE USSR: MAKARENKO EXPERIENCES IN COLOGNE \\ GORKI AND DZERJINSKI COMMUNE
}

\section{LA EDUCACIÓN INTEGRAL EN LA URSS: EXPERIENCIAS DE MAKARENKO EN LA COLONIA GORKI Y EN LA COMUNA DZERJINSKI}

Marilsa Miranda de Souza

Universidade Federal de Rondônia - Brasil

Marco Antônio de Oliveira Gomes

Universidade Estadual de Maringá - Brasil

\begin{abstract}
Resumo: O objetivo desse trabalho é discutir a educação integral a partir dos conceitos presentes na produção de Marx e de sua aplicação nas experiências educativas na União das Repúblicas Socialistas Soviéticas - URSS, dando destaque ao pensamento e às experiências desenvolvidas por Makarenko na Colônia Gorki, especialmente numa de suas comunas, a Comuna Dzerjinski. A educação na URSS buscou aplicar os princípios marxistas de servir a política do proletariado e estar combinada com o trabalho produtivo. Coube um papel de destaque ao trabalho do educador ucraniano que conseguiu unificar o trabalho produtivo à educação intelectual, incluindo a formação política, cultural, artística, além das atividades físicas. Por fim, o trabalho de Makarenko constituiu-se em um exemplo de coerência com os postulados pedagógicos forjados na URSS, que expressaram o objetivo teórico e prático de uma alternativa de superação da sociedade de classes.
\end{abstract}

Palavras-chave: Comunas. Educação Integral. Pedagogia Socialista.

\begin{abstract}
The objective of this work is to discuss integral education based on the concepts present in the production of Marx and its application in educational experiences in the Union of Soviet Socialist Republics - USSR, highlighting the thinking and activities developed by Makarenko in the Gorky Colony and the Commune Dzerzhinsky. Education in the USSR sought to apply the Marxist principles of serving the politics of the proletariat and being combined with productive work. The work of the Ukrainian educator who has succeeded in unifying productive work in intellectual education, including political, cultural, artistic formation, as well as physical activities, has played a prominent role. Finally, Makarenko's work constituted an example of coherence with the pedagogical postulates forged in the USSR, which expressed the theoretical and practical objective of an alternative to overcoming class society.
\end{abstract}

Keywords: Communes. Integral Education. Socialist Pedagogy. 
Resumen: El objetivo de este trabajo es discutir la educación integral a partir de los conceptos presentes en la producción de Marx y de su aplicación en las experiencias educativas en la Unión de las Repúblicas Socialistas Soviéticas - URSS, destacando el pensamiento y las actividades desarrolladas por Makarenko en la Colonia Gorki y en la Comuna Dzerzhinski. La educación en la URSS buscó aplicar los principios marxistas de servir a la política del proletariado y estar combinada con el trabajo productivo. En el trabajo del educador ucraniano ha logrado un papel destacado en el trabajo productivo a la educación intelectual, incluyendo la formación política, cultural, artística, además de las actividades físicas. Por último, el trabajo de Makarenko se constituyó en un ejemplo de coherencia con los postulados pedagógicos forjados en la URSS, que expresaron el objetivo teórico y práctico de una alternativa de superación de la sociedad de clases.

Palabras clave: Comunas. Educación Integral. Pedagogía Socialista.

\section{Introdução}

O objetivo desse trabalho é discutir a educação integral a partir dos fundamentos da educação socialista, que é antagônica aos processos de ampliação da jornada escolar, chamada inadequadamente de educação integral, instituída pelas políticas educacionais no Brasil. Partiremos do conceito de educação integral em Marx e sua aplicação nas experiências educativas na União das Republicas Socialistas Soviéticas - URSS, dando destaque ao pensamento e às experiências desenvolvidas por Makarenko na Colônia Gorki e na Comuna Dzerjinski.

Para Marx, o trabalho é a base essencial para a existência do homem, que se humaniza à medida que se apropria dos conhecimentos historicamente acumulados. No entanto, quando a divisão do trabalho é estabelecida e o indivíduo perde a totalidade de sua produção, torna-se meramente uma mão de obra alienada. Tendo por alternativa a superação dessa educação, Marx propõe uma educação integral ou a formação do homem omnilateral, que ofereça uma completa capacidade, adquirida pela apropriação dos conhecimentos historicamente acumulados (educação intelectual) aliada às riquezas materiais e a assimilação dos conceitos tecnológicos modernos para a prática do trabalho.

Esses princípios foram aplicados por Makarenko que, unindo o trabalho, o ensino e a vida de uma juventude antes marginalizada, criou um das mais importantes referências de coletividade, de participação e formação humana voltada aos interesses mais amplos da Revolução e da construção do socialismo soviético, ininterrupto ao comunismo. Essa educação integral desenvolveu diversas potencialidades humanas pela participação no 
trabalho, na arte, na cultura, na política, nas atividades físico-militares, na gestão e organização dos mais amplos processos, não apenas da Colônia ou Comuna, mas da sociedade em que essas instituições estavam envolvidas. A formação intelectual e política possibilitava que, paulatinamente, se atingisse o nível de consciência que se exige de um novo homem, de uma nova mulher, forjada nas experiências do proletariado soviético. Buscaremos demostrar que essas experiências não se constituíram como uma simples união entre trabalho e ensino, mas a proposição de alcançar a omnilateralidade do homem em sua totalidade.

\section{$O$ conceito marxista de educação integral}

Primeiramente faz-se necessário evidenciar a diferença entre educação de tempo integral e educação integral. A educação em tempo integral na sociedade capitalista assume meramente uma perspectiva unilateral " $\mathrm{O}$ âmbito escolar, as atividades formativas limitam-se a preparação do homem para ingresso no mercado de trabalho, mediante domínio de uma técnica e de conhecimentos desconectados de sua vida, portanto, apolíticos alienantes" (NEVES, 2009, p.875). A concepção de educação integral é uma concepção marxista. Marx, embora não tenha escrito nenhuma obra específica sobre educação deixou alguns princípios fundamentais. No "Manifesto do Partido Comunista", destaca-se uma orientação importante sobre a educação: "Ensino público e gratuito a todas as crianças. Abolição do trabalho das crianças nas fábricas em sua forma atual. Unificação do ensino com a produção material” (MARX; ENGELS, 1997, p. 21).

Com a fundação da Associação Internacional dos Trabalhadores (AIT) em 1864, sob sua chefatura, Marx, escreveu um texto intitulado "Instruções aos Delegados do Conselho Geral da AIT", no fim de Agosto de 1866. Publicado nos jornais The International Courier, n.os 6-7, 20 de Fevereiro, e n. ${ }^{\circ}$ s 8-10, 13 de Março, 1867, e Le Courrier International, n. ${ }^{\circ}$ s 10 e 11, 9 e 16 de Março, 1867, assim como na revista Der Vorbote n's 10 e 11, de Outubro e Novembro de 1866. Publicado segundo o texto de The International Courier. Essas instruções estavam organizadas em 11 pontos. O ponto numero 4 tratava da educação: 4. Trabalho juvenil e infantil (ambos os sexos). Recomenda que crianças a partir dos 9 anos devam se integrar ao trabalho produtivo e, explicando os motivos, completa afirmando que "nenhum pai nem nenhum patrão deveria ser autorizado a usar trabalho juvenil, exceto quando combinado com educação". Em seguida expõe sua concepção de educação:

Por educação entendemos três coisas: 
Primeiramente: Educação mental.

Segundo: Educação física, tal como é dada em escolas de ginástica e pelo exercício militar.

Terceiro: Instrução tecnológica, que transmite os princípios gerais de todos os processos de produção e, simultaneamente, inicia a criança e o jovem no uso prático e manejo dos instrumentos elementares de todos os ofícios.

Um curso gradual e progressivo de instrução mental, gímnica e tecnológica deve corresponder à classificação dos trabalhadores jovens. Os custos das escolas tecnológicas deveriam ser em parte pagos pela venda dos seus produtos. A combinação de trabalho produtivo pago, educação mental, exercício físico e instrução politécnica, elevará a classe operária bastante acima do nível das classes superior e média. É evidente que o emprego de todas as pessoas dos [9] aos 17 anos (inclusive) em trabalho noturno e em todos os ofícios nocivos à saúde tem de ser estritamente proibido por lei. (MARX; ENGELS, 2011, p.85).

Para a superação da passividade e subordinação a qual o trabalhador se submete no modo de produção capitalista, na perspectiva marxista, é necessário a união entre trabalho produtivo e formação intelectual. O trabalho manual e intelectual deve ocorrer junto, para a possibilidade da formação completa do homem, agregando em seu saber conceitos científicos, a educação física aliada aos conhecimentos tecnológicos que lhe permita a compreensão da totalidade da produção.

A formação integral (omnilateral) é uma educação completa, capaz de oferecer aos sujeitos a compreensão não só das partes, mas do todo que a compõe, nas características mais complexas, possibilitando o domínio do conhecimento e do trabalho produtivo. Não basta o ensino voltado apenas à prática ou apenas à teoria. O que Marx defende é a união entre teoria e prática, a ideia que "o homem se apropria de sua essência universal de forma universal, quer dizer, como homem total”. (MARX, 1985, p. 147). No O Capital, citando um relatório de inspeção de fábrica Marx defende uma educação integral com metade do dia na escola e metade no trabalho produtivo, pois se descansa e se distrai uma em relação à outra.

A coisa é simples. Aqueles que só permanecem na escola metade do dia estão sempre lépidos, em regra dispostos e desejosos de aprender. O sistema de metade trabalho e metade escola torna cada uma das duas ocupações descanso e recreação em relação à outra, sendo por isso mais apropriado para a criança do que a continuação ininterrupta de uma das duas. Um menino que desde cedo fica sentado na escola, especialmente no verão, não pode concorrer com outro que chega alegre e animado de seu trabalho. (MARX, 1968, p. 553-554). 
A concepção marxista compreende as relações históricas que constitui o homem, bem como o seu trabalho, aspecto que o torna um ser real e concreto na sociedade. A educação omnilateral deve possibilitar a relação teoria e prática, do especifico com o conjunto de conhecimentos existentes, capacitando o homem a construir uma sociedade plenamente igualitária.

No modo de produção capitalista a divisão do trabalho manual e intelectual, fornece ao homem a formação unilateral, ou seja, o homem começa a ter cada vez mais um conhecimento parcial, limitado. Deixa de compreender o processo produtivo como um todo complexo. O conhecimento específico e dividido o faz permanecer e contribuir para a divisão da sociedade e, consequentemente, das classes. “A divisão cria unilateralidade e, sob o signo da unilateralidade, justamente, se reúnem todas as determinações negativas, assim como sob o signo oposto, o da onilateralidade, [...] reúnem-se todas as perspectivas positivas da pessoa." (MANACORDA, 2007, P. 78). Desta forma, compreendemos que, com a formação unilateral do homem, correrá o trabalho negativo, aquele que o faz ser estranho a si mesmo, que nega a sua própria existência, tornando-o dominado. A fragmentação em sua formação, o faz ser um homem parcial, dividido. Nesse sentido Manacorda afirma que:

A onilateralidade é, portanto, a chegada histórica do homem a uma totalidade de capacidades produtivas e, ao mesmo tempo, a uma totalidade de capacidades de consumo e prazeres, em que se deve considerar sobretudo o gozo daqueles bens espirituais, além dos materiais, e dos quais o trabalhador tem estado excluído em consequência da divisão do trabalho. (MANACORDA, 2007, p. 89).

A concepção de educação de Marx é compreendida como uma concepção de educação integral e orientou todos os processos de educação nos países socialistas. A primeira experiência de aplicação desses princípios ocorreu após a Revolução de 1917 na Rússia, com a fundação das Repúblicas Socialistas Soviéticas - URSS.

\section{A educação integral na União Soviética}

A revolução de outubro de 1917, dirigida pelo Partido Bolchevique e liderada por Lênin, fez da Rússia o primeiro país no mundo a implantar o modo de produção socialista, embasado no pensamento marxista, transformando-se na grande e poderosa União das Repúblicas Socialistas Soviéticas - URSS. O país se dedicou a realizar a redistribuição de todas as terras, nacionalização dos bancos e o controle das fábricas pelos trabalhadores.

Após a vitória bolchevique de outubro de 1917, a Rússia enfrentou a guerra civil que findou apenas em 1921. O estado era de flagelo, pobreza e dificuldades materiais: a fome 
espalhando-se pelas diferentes regiões do país, analfabetismo e destruição sem precedentes. Milhares de crianças e jovens órfãos, prostituição e criminalidade eram a herança de séculos de um regime decrépito e desacreditado, além da aventura de uma guerra imperialista que não saciou os apetites burgueses. Documentos do censo da última década do século XIX apontam que somente $29 \%$ dos homens eram alfabetizados e $13 \%$ das mulheres.

A ignorância, o analfabetismo, a ausência de direitos e a miséria mais terrível foram a sorte das massas populares do império tzarista. No início do século XX a Rússia era, especialmente no setor da educação, um dos países mais atrasados do mundo. A maioria da população era analfabeta. Os documentos do censo nacional realizado em 1897 demonstram que entre os homens apenas $29 \%$ sabiam ler e escrever, enquanto a porcentagem das mulheres alfabetizadas era muito mais baixa ainda: 13 em cada 100. Por outro lado, 4 em cada 5 crianças não tinham a mínima possibilidade de estudar. [...]. Nas atuais repúblicas de Tadjiquistão, Kirguízia e Uzbequistão a falta de instrução era quase total; os índices revelam que, naquela época e até o início de nosso século, o analfabetismo atingia $98 \%$ da população. Cerca de 50 povos que hoje integram a União Soviética não tinham sequer a sua escrita codificada. (CAPRÍLES, 2007, p.18).

A opressão histórica podia ser vista nas condições de trabalho dos professores, na exclusão dos trabalhadores do sistema escolar e nos altos índices de analfabetismo. Além das condições descritas acima, era imperioso afrontar as velhas mistificações burguesas difundidas pelo discurso de inúmeros professores identificados com a velha ordem.

De fato, os bolcheviques ao conquistarem o Estado assumiram a tarefa de superar o descaso acerca do sistema educacional. A nova forma de gestão da educação tornou a escola da URSS pública, gratuita, laica e democrática. Devido a esse intenso movimento em defesa da emancipação dos trabalhadores, $100 \%$ da população Russa foi alfabetizada na escola socialista (MARTEN, 2003). A educação da URSS teve um grande salto quantitativo. Com a expansão das escolas, universidades e creches, ocorreram também profundas mudanças na forma organizacional do sistema escolar.

Para a superação revolucionária da ordem czarista e semifeudal em decomposição, ainda que imersos na guerra civil que ocorre logo após a Revolução de outubro de 1917, os revolucionários empreenderam grandes esforços teóricos e práticos no campo da educação com objetivo de colocarem operários e camponeses na direção da sociedade.

A respeito do tema, Lênin asseverou:

[...] o quê e como aprender? E neste problema o essencial é que, com a transformação da velha sociedade capitalista, o ensino, a educação e a 
instrução das novas gerações, destinadas a criar a sociedade comunista, não podem seguir sendo o que eram. Pois bem, o ensino, a educação e a instrução da juventude devem partir dos materiais que nos têm legado a antiga sociedade. Não podemos edificar o comunismo se não é a partir da soma de conhecimentos, organizações e instituições, com o acervo de forças e meios e forças humanas que temos herdado da velha sociedade. Só transformando radicalmente o ensino, a organização e a educação da juventude, conseguiremos que os resultados dos esforços da jovem geração seja a criação de uma sociedade que não se pareça à antiga (a burguesa), a saber, da sociedade comunista. (LÊNIN, 1977, p. 203).

A educação passa a ser repensada pelos comunistas, que compreendem ser esta uma arma ideológica que deve estar a serviço do proletariado. O princípio da educação esteve centrado no objetivo de estabelecer a vinculação entre o trabalho, a ideologia do proletariado e o coletivismo.

A pedagogia que nasceu das lutas do proletariado por sua emancipação apresentava como princípios basilares a concepção marxista de articulação imperativa entre teoria e prática, o esforço em conjugar a instrução com o trabalho produtivo, expandindo o horizonte cultural dos alunos. A educação dos trabalhadores deveria ser alicerçada em princípios opostos daqueles impostos pelo Estado burguês. "Os revolucionários sabiam que a criação de novas relações sociais necessitava de uma escola que contribuísse para a formação de um novo tipo de homem" (ABREU, 2015, p. 332) Em outras palavras, a tarefa que se colocava para os revolucionários era a construção material e social de uma nova sociedade que se pautava em novos valores. Para isso, havia a necessidade de formação do novo homem.

A perspectiva da educação integral em Lênin se evidencia pela defesa na formação de um novo homem, de uma nova mulher, mas ele apresenta também que naquele momento as condições socioeconômicas, políticas e sociais ainda não permitiam uma educação integral em conformidade com os princípios marxistas, mas que as próximas gerações poderiam construí-las.

A linha ideológica que guiou os caminhos da educação neste país foi o PCUS (Partido Comunista da União Soviética), o pensamento de Marx e Engels e o pensamento Leninista. Embora enfrentando muitas dificuldades, a educação na URSS obteve um grande avanço em seu objetivo de construir uma educação integral. Destaca-se a contribuição de três educadores em especial: Makarenko, Pistrak e Krupskaya que se dedicaram ativamente na construção de um novo modelo de escola, que fosse espaço de resistência e luta revolucionária contra a cultura capitalista disseminada até então.

A educação na URSS deveria servir a política do proletariado e estar combinada com o trabalho produtivo. Por isso, nos anos seguintes a Revolução Bolchevique de Outubro de 
1917 foram criadas na União Soviética diversas escolas-comunas. Essas instituições tinham como objetivo central a aplicação da linha marxista de educação, visando vincular o ensino ao trabalho produtivo e desenvolver uma construção coletiva. Surge nesse período a EscolaComuna P. N. Lepeshinskiy que foi administrada por Pistrak.

Para Pistrak (2005, p. 37). “[...] a escola deve explicar a cada um os objetivos da luta, contra o que lutar e por que meios, o que cada aluno deve criar e construir, e como [...] o conteúdo do ensino deve servir para armar a criança para a luta e para a criação da nova ordem”. Na luta em que se trava entre e a reação e a revolução, entre o passado e o presente, é preciso de fato, levando o estudo da realidade atual até este ponto, inculcar na nova geração que cada adolescente deve ser, ou melhor, já é, um soldado engajado na luta, devendo assumir o objetivo de se armar dos conhecimentos necessários para apoiar a luta, estudando convenientemente as armas do adversário e aprendendo a empregá-la no interesse da revolução e, sabendo também, ao mesmo tempo, utilizar praticamente suas próprias armas: em outras palavras, seu objetivo deve ser o de adquirir a ciência. Lutar e construir - isto deve ser aprendido por cada um de nossos alunos. (PISTRAK, 2005, p.36-37)

Não se trata de formar um homem ideal, mas de construir relações sociais fundamentalmente diferentes daquelas historicamente construídas. Recordemo-nos que a Rússia principiou o enfrentamento das questões relativas à instrução pública paralelamente ao momento que eram computadas as baixas geradas pela guerra. Tratou-se de uma tarefa complexa em que não se limitava meramente a combater o analfabetismo, mas igualmente a mentalidade burguesa ainda presente entre vastos segmentos da população russa. (GOMES; SOUZA; MARTINS, 2017).

A concepção de homem que a sociedade almeja formar determina a qualidade do ensino que cada ser humano irá receber. Por isso, é preciso que os alunos não apenas estudem os fenômenos e suas ações, mas que vinculem estudo, trabalho, atividades políticas e culturais, não deixando em segundo plano a contribuição com a construção da nova sociedade, pois para o marxismo, a escola é compreendida como sendo a arma ideológica da revolução. Dessa forma, a educação socialista preza pela formação integral da classe operária.

A concepção de educação socialista busca quebrar a perspectiva de formação restrita do homem. Desse modo, a escola necessita ensinar a todos, para que possam compreender os processos sociais em sua totalidade. É prescindível que a educação instrua o homem para cooperar com a construção da nova sociedade. Portanto, os estudantes devem ser educados para desempenharem o trabalho intelectual, assim como o trabalho manual. Este último, não 
deve ser concebido como inferior e nem mesmo secundário. A nova fase de desenvolvimento da URSS exigia que o proletariado unisse o trabalho intelectual ao trabalho manual como contribuição necessária para a formação integral dos cidadãos russos.

\section{Apontamentos sobre a pedagogia socialista de Anton Semiónovitch Makarenko}

O mais importante educador na URSS foi Anton Makarenko. Verdadeiramente marxista e disciplinado no cumprimento das diretrizes do Partido Comunista da União Soviética, se dedicou ativamente na construção de uma educação que tinha como base o desenvolvimento do espírito coletivo. Um exemplo importante a respeito da construção de um novo modelo de ensino foi realizado na Colônia Gorki e na Comuna Dzerjinski, onde os gorkianos trabalhavam para manterem o coletivo funcionando. Seus interesses estavam relacionados ao próprio trabalho, como maneira de encontrar uma libertação de seu passado e presente, possibilitando reiniciarem suas vidas produtivas na nova e revolucionária sociedade soviética recém-estabelecida. Makarenko talvez tenha sido o educador que levou às consequências mais radicais as questões do espírito de grupo e do trabalho coletivo.

A União Soviética apresentava altos índices de jovens delinquentes que vinham desde o período anterior à revolução. O problema da marginalidade passa a ser repensado pelos comunistas. Em vez de serem excluídos da sociedade esses jovens delinquentes são inseridos a nova sociedade no intuído de contribuírem com o processo produtivo e desenvolvimento social daquele país. A experiência educativa de Makarenko na Colônia Gorki foi relatada na sua obra Poema Pedagógico, uma coleção de 03 volumes, onde o autor relata as dificuldades e êxitos obtidos em seu trabalho com jovens delinquentes na Colônia. E sua prática na Comuna Dzerjinski ocasionou na escrita das obras: A marcha dos anos 30 e Bandeira nas Torres, além de algumas peças teatrais.

É a partir da compreensão exata deste cenário que se insere a experiência de Anton S. Makarenko (1888-1939), que consagrou sua trajetória a educar, arquitetar e organizar um processo educativo constituído nas bases do pensamento socialista que superasse a educação liberal burguesa.

A partir dos êxitos desenvolvidos em suas experiências, especialmente na Colônia Gorki, Makarenko desenvolveu uma proposta de educação socialista em que criticava a Pedologia, por "psicologizar" demais a educação, o pragmatismo da Escola Nova que tinha alguma influência na URSS, o sistema de complexos, etc. Em agosto de 1922, enviou um 
relatório ao Instituto Central de Organização da Instrução Pública, propondo algumas medidas para o desenvolvimento de uma pedagogia socialista:

$1^{\circ}$ Elaboração de um método científico de investigação pedagógica. Segundo os métodos atuais, a criança é o objetivo principal da investigação pedagógica. Acredito que este não é um princípio correto. A ciência pedagógica deve considerar o fato, o fenômeno pedagógico, como o objetivo final dessa investigação.

$2^{\circ}$ Aprofundar a atenção em relação à coletividade infantil como um todo orgânico. Para isto é necessário reestruturar toda a psicologia do trabalhador escolar.

$3^{\circ}$ Renunciar completamente a idéia de que para existir uma boa escola é necessário, antes de tudo, bons métodos para aplicar nas aulas. O que necessita para obter uma boa escola é um sistema cientificamente organizado, compreendendo todas as suas influências. $4^{\circ}$ A psicologia não deve ser o fundamento da pedagogia e sim a continuação dela, e assim deve ser entendido o processo de realização da lei pedagógica.

$5^{\circ}$ A escola russa de trabalho tem que ser reestruturada completamente já que, na sua essência, é uma visão burguesa. A base fundamental da escola russa não deve partir da teoria "ocupação-trabalho", senão da sua antítese dialética: "trabalho- preocupação". Somente a organização da escola como uma função econômica a tornará socialista (MAKARENKO, apud CAPRILES, 1989, p. 91-92).

As considerações de Makarenko sobre a vinculação de ensino ao processo produtivo, a coletivização e métodos de ensino são fundamentais na construção de uma educação socialista. É justamente por isso, que as experiências que desenvolveu são as melhores referências para a construção de uma educação integral no sentido amplo do termo, como preconizou Karl Marx.

Seu trabalho se notabilizou pela educação de crianças e jovens provenientes dos filhos das classes trabalhadoras marginalizadas pelas estruturas semifeudais do Império czarista da Rússia que foi solapado pela Revolução de 1917. Dessa forma, não nos parece possível analisar a trajetória intelectual de Makarenko de forma desvinculada dos primórdios do século XX na Rússia e de suas jornadas revolucionárias. Sua trajetória teve início no momento de institucionalização da escola, ainda privilégio de poucos, sob o czarismo, e o desafio da criação da escola única, após a ascensão dos bolcheviques. Ao longo dos primeiros anos da Revolução Russa (1917), Makarenko desenvolveu ativamente um trabalho educativo com crianças e adolescentes, muitos deles órfãos de pai e mãe na Ucrânia, uma das repúblicas que constituíram a União Soviética. 
A escola soviética poderia e deveria ser, segundo Makarenko, a instituição social de participação das crianças, lugar de formação e de participação, de criação de uma nova sociabilidade, da subordinação entre iguais, da personalidade comunista, deveria existir um trabalho de organização da coletividade, com um tempo relativamente longo para que se pudesse avaliar os resultados. (LUEDEMANN, 2002, p. $385)$.

Foi um dos pioneiros a introduzir uma educação única para homens e mulheres num mesmo espaço de formação (CAPRILES, 1989, p. 98). Conforme Luedemann (2002, p.146), a presença feminina foi um elemento a mais na construção do coletivismo.

A proposta do educador coadunava-se com a perspectiva de superação dos resquícios do czarismo, marcados pela fome, miséria, ausência de direitos sociais dos trabalhadores russos. O objetivo pautava-se na ideia que crianças e adolescentes assumissem o comando de suas vidas. A vida prática seria o parâmetro do trabalho vivo de uma ação pedagógica intencional e planejada em oposição aos posicionamentos espontaneístas, especulativos e abstratos. Segundo Manacorda,

Makarenko elabora, então, uma pedagogia original, antirousseauniana e não-espontânea, embora toda a literatura pedagógica da época fosse tal, mas voltada para uma exigentíssima 'educação dos sentimentos', frequentemente, num aparente contraste com os interesses das crianças, assim como elas o entendiam. Esta educação tão exigente se realiza especialmente através da conexão entre instrução e trabalho produtivo, do qual as crianças podem ver os frutos concretos e no qual são necessariamente levadas à colaboração com o coletivo de que são parte. Ao lado da educação dos sentimentos e do trabalho, o 'coletivo' é o outro grande motivo da pedagogia de Makarenko: mas ele constatou que o próprio coletivo pode ter validade educativa somente se não lhe faltam perspectivas de vida e de alegria, 'da alegria do amanhã', como ele diz. A educação dos sentimentos é viável se se conseguem essas perspectivas de tal forma que de individuais tornamse de grupo e do grupo cheguem à classe social, ao povo todo e a todos os homens do mundo. O trabalho, a colaboração, as perspectivas de alegria e a felicidade para todos os homens (e não paenas a felicidade do indivíduo, expressada no Setecentos por Locke, Rousseau e pelos revolucionários da América e da França) eram os métodos e os fins da Pedagogia de Makarenko, tão exigente, quanto otimista. (MANACORDA apud LUEDEMANN, 2002, p. 24-25).

Em oposição ao idealismo pedagógico, o educador ucraniano criticava a ideia de desenvolvimento natural do indivíduo. Em oposição aos ideais abstratos e especulativos, elaborou uma proposta de sociologia educacional a partir das referências de $\mathrm{O}$ estado e a 
revolução de Lênin com o objetivo de educar para a abolição das classes. Tratava-se de uma educação diferente daquela ofertada pela burguesia. Em oposição aos ideais eternos e abstratos, definia tarefas concretas, fruto de um planejamento consciente e racional das necessidades sociais (FILONOV, 2010). Uma educação de homens e mulheres com diferentes capacidades e diferentes necessidades, mas com os direitos assegurados.

Em outras palavras, sua proposta pedagógica é desenvolvida organicamente com as condições concretas da realidade e objetivando a construção de uma nova cultura, que deve ser orientada para os interesses do coletivo e não para o individualismo, o que o afasta definitivamente das concepções vinculadas ao movimento da Escola Nova.

A nossa educação deve ser comunista e cada pessoa que educamos deve ser útil à causa da classe operária. Este princípio, generalizador e necessário, pressupõe precisamente formas distintas para a execução da tarefa de acordo com a variedade do material e as suas diversas formas de aplicação na sociedade. Qualquer outro princípio não é mais do que uma despersonalização. (MAKARENKO, 2010, p. 48-49).

Na colônia Gorki, Makarenko trabalhou com crianças e jovens órfãos, abandonados ou em situação de delinquência que necessitavam passar por um processo de ressocialização. Diante das condições materiais decorrentes do pós Primeira Guerra e Guerra Civil, as dificuldades materiais eram imensas. Era imprescindível manter-se funcionando e, ao mesmo tempo, possibilitar a formação dos educandos.

Havia na nossa enlouquecedora miséria um lado bom, que depois veio a nos faltar. Estávamos também nós, igualmente esfomeados e pobres. Naquele tempo, quase não nos pagavam. Contentávamos com a mesma "mistela", e o nosso vestuário era mais ou menos tão maltrapilho como o dos rapazes. As minhas botas ficaram sem sola durante quase todo o inverno, com uma ponta de meia russa a escapar-se para fora (MAKARENKO, 1980, p. 41).

Diante de tantas dificuldades, especialmente de alimentos, a necessidade de produzir para a sobrevivência fez do trabalho um aspecto central em sua obra. Ressalte-se que esta opção não se tratou de mera especulação.

Na vida da coletividade educativa, Makarenko destinou um lugar particular ao trabalho, ligado ao estudo das bases das ciências e a uma ampla educação cívica, política e moral. Suas ideias principais, no domínio da educação pelo trabalho, podem assim ser resumidas: a) o trabalho só se tornará um instrumento eficaz da educação comunista se for integrado ao conjunto da organização do processo educativo; além disso, este sistema não tem nenhum sentido se todas as crianças e adolescentes não participarem das formas de trabalho socialmente 
útil, adaptadas às suas idades; b) é preciso que estas diferentes formas de trabalho, enquanto participação obrigatória da autogestão e do trabalho produtivo, sejam organizadas sobre a base técnica mais moderna possível e tendo por eixos uma criação técnica seletiva, assim como um trabalho gratuito efetuado no interesse de todos: uma vez preenchidas essas condições, as crianças e adolescentes tiram partido da riqueza das relações que determinam o desenvolvimento harmonioso e livre da personalidade; c) o coletivo, seus órgãos e seus delegados devem se encarregar, em medida sempre crescente, de organizar o trabalho e de tomar as decisões relativas à repartição dos benefícios, à compatibilização dos salários, à utilização de diversos estimulantes materiais e morais e à organização do consumo (FILONOV, 2010, p. 20).

Para o educador ucraniano, o trabalho não era um aspecto separado da vida ou dos estudos. "A escola makarenkiana é organizada de acordo com os princípios da instrução geral e do trabalho produtivo, retirando-se a centralidade da sala de aula" (LUEDEMANN, 2002 p. 26). Entretanto, sabia dividir o tempo entre trabalho produtivo e tempo de estudo em sala de aula. Makarenko discordava de Pistrak que propunha a metodologia dos complexos. Para ele o trabalho não é educativo por si mesmo. Para Makarenko, não se pode enveredar para o praticismo. Não é necessário se evidenciar a prática em todas as atividades educativas, o tempo todo e se deve proporcionar tempos específicos para o estudo.

Seguramente recordarão dos danos causados pela teoria de que o processo laboral deve estar 'vinculado' ao programa de estudo. Como 'queimamos os miolos' com este maldito problema! Os meninos faziam um tamborete e tínhamos de entender a forma como isso se ligava à geografia e à matemática (risos). Eu ficava possesso quando aparecia uma comissão e não encontrava correspondência entre o tamborete e a língua russa (gargalhadas). Até que decidi mandar tudo isso 'pro inferno' e comecei a afirmar sem maiores cuidados que não devia existir relação alguma. (MAKARENKO, 2002, p. 390).

Para ele o trabalho como principio educativo "solo es posible formando parte del sistema general", de forma a unir a educação política e a educação social: "De cualquier modo, si el trabajo no va acompañado de la enseñanza, si no va unido a la educación política y social, no dará provecho educativo, será un processo neutral”. (MAKARENKO, 1975, p. 19). A educação, a partir do trabalho, deveria levar em conta o seu caráter produtivo ou socialmente "útil", no caso da colônia resolver os problemas concretos que havia no local. (MAKARENKO, 1975, p. 92). Assim, o trabalho coletivo na colônia era fundamental não apenas para que os alunos se apropriassem das técnicas de produção, mas também para a 
construção da nova ordem. Para Makarenko o coletivo "[...] é um organismo social vivo e, por isso mesmo, possui órgãos, atribuições, responsabilidades, correlações e interdependências entre as partes. Se tudo isso não existe, não há coletivo, há uma simples multidão, uma concentração de indivíduos" (MAKARENKO, apud CAPRILES, 1989, p. 13).

Para Makarenko, o trabalho coletivo deve expressar um modo socialista de vida, uma mentalidade coletivista, onde o bem-estar de todos é o bem-estar de cada um. Para ele a coletividade é uma microestrutura social em que se reproduz um tipo de relações característico para todo um conjunto de relações.

A coletividade só pode se desenvolver baseada em uma atividade que seja claramente útil à sociedade, uma atividade concreta, consciente. Essa coletividade cria particularidades quando defende interesses comuns, luta por direitos pessoais ou sociais. Para Makarenko, o processo realizador da soberania da coletividade está no problema da personalidade e da coletividade. É preciso criar as condições para o desenvolvimento harmônico e livre do individuo para a educação coletivista: "Para trabalhar com uma só pessoa tem que conhecê-la e cultivá-la. Se eu imagino as pessoas como grãos amontoados, se não as vejo na escala da coletividade, se as abordo sem ter em conta que são parte da coletividade, não estarei em condições de trabalhar com elas" (MAKARENKO, 1986, p. 86).

A partir das experiências adquiridas, Makarenko sistematizou os parâmetros para constituição e desenvolvimento da coletividade escolar, analisando a organização da coletividade e operacionalização da autogestão da comuna.

A participação na produção dos alunos da colônia Gorki e da comuna Dzerjinski quatro horas por dia era, para Makarenko, uma necessidade ligada às dificuldades encontradas pelo país após a guerra civil. No programa, o trabalho era colocado ao lado do estudo, das atividades esportivas, artísticas, recreativas e sociais; o efeito econômico do trabalho dos alunos era parte de sua iniciação nas relações de produção, de distribuição e de consumo, sem nenhuma consideração de autonomia financeira. (FILONOV, 2010, p. 21)

Os fundamentos da proposta pedagógica de Makarenko eram orientados pela participação dos jovens, a partir do princípio de auto-organização, que estimula os jovens a participação das decisões de seu espaço coletivo. Dessa forma, os educandos eram estimulados a envolver-se com os problemas da colônia, identificando-os, propondo alternativas e avaliando os caminhos que se colocavam. Para Makarenko,

[...] o tempo de educar contempla todos os tempos sociais, inclusive da cultura, do lazer, do descanso, até mesmo quando as crianças estão se preparando para dormir. A educação da coletividade, de todas as crianças, em suas diferentes personalidades, deve tomar 
tanto os diferentes momentos de suas vidas, os espaços diferenciados, quanto o desenrolar do processo, não se deixando enganar pela análise de um ou de outro episódio isolado da ação dos educandos. (FILONOV, 2010, p. 34)

Por se pautar por um projeto educacional que se propõe a contribuir para a construção do socialismo, as ideias de Makarenko abarca outras formas e dimensões dos processos de desenvolvimento do homem. Não se trata simplesmente de uma preparação para a vida adulta, mas de uma proposta que vinculava escola, trabalho e participação dos alunos nas decisões das comunas.

Outro aspecto que identifica as experiências de Makarenko com a educação integral é a atividade física que se destacou como exercícios militares e jogos. Makarenko defendia os jogos como recursos pedagógicos essenciais (MAKARENKO, 1979, p. 213).

\begin{abstract}
Não sei porquê, talvez por virtude de um instinto pedagógico, ignorado, lancei-me nos exercícios militares.

Já antes eu dava aos colonos lições de cultura física e de preparação militar. Não fora nunca um monitor qualificado, mas não tínhamos meios de mandar vir um especialista desses. Conhecia apenas o manual do soldado, a ginástica militar, e sabia exatamente o que se refere ao papel da companhia em combate. Sem me perder em raciocínios e sem a menor crise de consciência pedagógica, treinei as crianças em todas aquelas coisas úteis.

Os colonos prestaram-se àquilo com prazer. Todos os dias, depois do trabalho, durante uma hora ou duas, toda a colónia se exercitava na praça de armas, que era o nosso pátio quadrado. (MAKARENKO, 1980, p. 199).
\end{abstract}

Os exercícios físico-militares contribuíram para dar mais unidade e disciplina ao coletivo. Reforçaram-se os princípios do centralismo democrático e a hierarquia a tal ponto que passaram a se organizar como destacamentos, expressão utilizada pelos exércitos revolucionários.

Algumas das qualidades do cidadão soviético que Makarenko queria formar foram: a) um profundo sentimento do dever e da responsabilidade para com os objetivos da sociedade; b) um espírito de colaboração, solidariedade e camaradagem; c) uma personalidade disciplinada, com grande domínio da vontade e com vistas aos interesses coletivos; d) algumas condições de atuação que impedissem a submissão e a exploração do homem pelo homem; e) uma sólida formação política; - uma grande capacidade de conhecer os inimigos do povo.

Em síntese, sua proposta aponta para uma escola única organizada em coletividade, capaz de combinar todas as diferenças com base nos direitos iguais de uma sociedade que busca abolir a propriedade privada dos meios de produção. Makarenko procurou moldar o 
novo homem, que achava possível e necessário, para a Rússia pós-revolução e desenvolveu uma avançada experiência de educação integral dentro da perspectiva marxista, pois possibilitou o principio comunista de coletividade, onde educandos exerciam diferentes atividades: o trabalho produtivo com diferentes modalidades e especialidades técnicas, o estudo teórico, a política, a cultura, o lazer, a ginástica, o exercício militar, etc. As lições de Makarenko, bem como de outros educadores forjados na luta revolucionária soviética, nos auxiliam na análise da realidade e na formulação de proposições que levem em conta a realidade que se inscreve a luta de classes no mundo contemporâneo.

Dessa forma, não nos parece possível dissociar a obra de Makarenko do projeto de uma pedagogia socialista. A construção do Estado soviético e os avanços que ocorreram no período constituem em um legado que não pode ser destruído pelos apóstolos do capital. $\mathrm{O}$ esforço de educador ucraniano apresenta-nos uma série de elementos sobre o papel da educação e reafirma como ela pode contribuir para a efetivação dos interesses e objetivos do proletariado.

\section{Considerações finais}

Não deve ser novidade para os educadores comprometidos com a superação da ordem burguesa que as possibilidades de constituição de uma educação integral são limitadíssimas dentro da ordem capitalista. Apesar das contradições que atravessam a escola e dos espaços ocupados por professores e alunos que buscam superar as condições materiais que se inserem, não há como negar o caráter hegemônico da ideologia burguesa sobre a educação. No entanto, tais constatações não implicam na impossibilidade de ruptura histórica com o capital.

Faz-se necessário compreender a escola como um espaço conflituoso e não imune às lutas de classes, permeado permanentemente pelas contradições da sociedade de classes. Lembremo-nos que as escolas mantidas pelo Estado são aquelas destinadas fundamentalmente aos trabalhadores e seus filhos, que muitas vezes encontram nestes estabelecimentos o único espaço de assimilação do conhecimento científico e sistematizado.

Assim, as lutas em torno das diferentes proposições pedagógicas constituem em um elemento da contradição maior: a luta entre capital e trabalho potencializada pela crise estrutural do capitalismo que arrasta cada vez mais homens e mulheres para a condição de miséria e a barbárie materializa-se de forma mais contundente no horizonte dos trabalhadores. Fome, desemprego ou subemprego, guerras patrocinadas pelo imperialismo, desastres 
ecológicos são elementos que não podem ser vistos como fatos isolados. Porém, "só a exposição das cicatrizes e da miséria produzidas pelo capitalismo não bastará para achar uma saída 'pela esquerda' para a crise atual” (BORON, 2004, p. 60). A saída "pela esquerda" é a revolução, e para construí-la faz-se necessário transformar a escola numa trincheira da luta de classes, especialmente se utilizando dela para elevar a consciência das massas como nos ensina Marx (2010, p. 151):

\begin{abstract}
A arma da crítica não pode, é claro, substituir a crítica da arma, o poder material tem de ser derrubado pelo poder material, mas a teoria também se torna força material quando se apodera das massas. A teoria é capaz de se apoderar das massas tão logo demonstra ad hominem, e demonstra ad hominem tão logo se torna radical. Ser radical é agarrar a coisa pela raiz. Mas a raiz, para o homem, é o próprio homem.
\end{abstract}

Assim, se cabe aos trabalhadores constituir-se na força material da revolução, cabe igualmente que se apoderem das "armas espirituais". Esse é o grande desafio que temos quando discutimos o papel da escola na sociedade capitalista.

Os postulados pedagógicos forjados na URSS expressaram o objetivo teórico e prático de uma alternativa de superação da sociedade de classes e formar a totalidade das dimensões humanas, ao contrário da educação de tempo integral em curso nas nossas escolas que tem servido apenas para manter confinadas dentro de seus muros crianças e adolescentes das classes trabalhadoras como medida de segurança contra a criminalidade no contexto de crise do capitalismo.

\title{
REFERÊNCIAS
}

ABREU, Malila da Graça Roxo. O legado educacional da transição russa: elementos para análise da política educacional do período pós-revolucionário. Revista HISTEDBR On-line, Campinas, $n^{\circ} 65$, out. 2015.

BORON, Atílio Alberto. A. Os "novos leviatãs" e a pólis democrática: neoliberalismo, decomposição estatal e a decadência da democracia na América Latina. In: Pósneoliberalismo II: Que estado, que democracia? CLACSO. Rio de Janeiro. Vozes, 2004.

CAPRILES, René. Makarenko: o nascimento da Pedagogia Socialista. São Paulo: Scipione, 2007.

FILONOV, George Nikolaevich. Ensaio. In: FILONOV, George Nikolaevich; BAUER, Carlos; BUFFA, Ester (orgs.) Anton Makarenko. Recife: Fundação Joaquim Nabuco, Editora Massangana, 2010. 
GOMES, Marco Antônio de Oliveira; SOUZA, Marilsa Miranda de; MARTINS, Márcio Marinho. Apontamentos sobre o legado da Revolução Russa de 1917. Germinal: marxismo e educação em debate, Salvador, v. 9, n. 3, ago. 2017.

LENIN, Vladimir Ilyich. I. Tarefas das organizações juvenis. In: LENIN, Vladimir Ilyich. Obras Escolhidas Em Doze Volumes. Moscou: Progresso, 1977. v. 11. p. 203-220.

LUEDEMANN, Cecília da Silveira. Anton Makarenko: vida e obra - a pedagogia na revolução. São Paulo: Expressão Popular, 2012.

MAKARENKO, Anton Semonovich. Os objetivos da educação. In: Filonov, G. N.; BAUER, Carlos; BUFFA, Ester (orgs.) Anton Makarenko. Recife: Fundação Joaquim Nabuco, Editora Massangana, 2010.

. Problemas da educação escolar. Tradução de M. D. Vinográdova. Moscou: Edições Progresso, 1986.

. Poema Pedagógico. Primeira Parte. Tradução das Edições Francesas por M. Rodrigues Martins, Livros Horizontes, 1980.

. Textos de Makarenko. In: LUEDEMANN, C. Anton Makarenko: vida e obra pedagogia na revolução. São Paulo: Expressão Popular, 2012.

Problemas de la educación escolar soviética. Moscou: Progresso, 1975.

Problemas da educação escolar. Tradução de M. D. Vinográdova. Moscou: Edições Progresso, 1986.

MANACORDA, Mário Alighieri. Marx e a pedagogia moderna. (Trad.) OLIVEIRA, N. R de. Campinas, SP: Alínea, 2007.

MARTENS, Ludo. Stálin: um novo olhar. Rio de Janeiro: Editora Revan, 2017 MARX, Karl. O Capital. Rio de Janeiro, Civilização Brasileira, 1968.

. Manuscritos: economía y filosofía. Madrid: Alianza Editorial, 1985.

. Crítica da filosofia do direito de Hegel. São Paulo: Boitempo, 2010.

MARX, Karl; ENGELS, Friedrich. Textos sobre Educação e Ensino. Campinas, SP: Navegando, 2011.

Manifesto do Partido Comunista. Lisboa: Editorial Avante, 1997.

NEVES, Sandra Garcia. A produção omnilateral do homem na perspectiva marxista: a educação e o trabalho. Anais do IX Congresso Nacional de Educação - EDUCERE. 2009. Disponível em: http://educere.bruc.com.br/arquivo/pdf2009/3581_2062.pdf. Acesso em: 03 jun, 2016. 
PINEL, Walace Roza; RESES, Erlando da Silva. A pedagogia de Makarenko: aproximações de um modelo socioeducativo na Revolução Russa. Germinal: Marxismo e Educação em Debate, Salvador, v. 9, n. 3, dez. 2017.

PISTRAK, Moisey Mikhaylovich. Fundamentos da Escola do Trabalho. São Paulo: Editora Expressão Popular, 2005.

\section{$\underline{\text { SOBRE OS AUTORES }}$}

\section{Marilsa Miranda de Souza}

Doutora em Educação Escolar pela Universidade Estadual Paulista (UNESP). Professora do Programa de Pós-Graduação em Educação e do Departamento de Ciências da Educação da Universidade Federal de Rondônia (UNIR).Líder do Grupo de Pesquisa História, Sociedade e Educação no Brasil (HISTEDBR/UNIR). Vice-Líder do Grupo de Pesquisa Centro de Estudos Marxistas em Educação e História na Amazônia (CEMEHIA/UNIR). E-mail: marilsa.miranda@unir.br

\section{Marco Antônio de Oliveira Gomes}

Doutor em Educação pela Universidade Estadual de Campinas (UNICAMP). Professor do Programa de Pós-Graduação em Educação e do Departamento de Fundamentos da Educação da Universidade Estadual de Maringá (UEM). Membro do Grupo de Pesquisas em Fundamentos Histórico-Filosóficos da Educação. Membro do Grupo de Pesquisa sobre Política, Religião, Educação e Modernidade. E-mail: marcooliveiragomes@ yahoo.com.br 